\title{
Editorial: Instrumentos e práticas para a Ciência aberta no Direito processual penal - perplexidades e algumas possibilidades
}

Editorial: Instruments and practices for Open Science in
Criminal Procedure - perplexities and some possibilities

Bruna Capparelli

PhD candidate em Direito Processual Penal na Alma Mater Studiorum Università di Bologna, em cotutela com a PUCRS

Editora-assistente da RBDPP

bruna.capparelli2@unibo.it

http://orcid.org/0000-0003-1249-2658

\section{Nereu José Giacomolli}

Doutor em Direito Processual Penal pela Universidad Complutense de Madri Editor-chefe da RBDPP Professor titular de Direito Processual Penal na PUCRS nereu@giacomolli.com lattes.cnpq.br/5969235847033808 http://orcid.org/0000-0003-1753-0334

Resumo: O presente editorial traça uma reflexão sobre as intersecções e sobreposições de noções e interpretações do conceito de atribuição cientifica, open data e ciência aberta no Direito processual penal. Partindo da premissa de que a divulgação pública de dados e estatísticas em acesso aberto representa tanto uma garantia em relação à qualidade e seriedade da informação, como uma economia de tempo e recursos para as pesquisas científicas, neste editorial a atenção é concentrada sobre os critérios à disposição da comunidade científica para a validação da pesquisa.

Palavras-chave: editorial; acesso de dados; validação da pesquisa; processo penal. 
ABSTRACT: The present editorial draws a reflection on the intersections and overlaps of notions and interpretations of the concept of scientific assignment, open data and open science in Criminal Procedure. Based on the premise that the public disclosure of data and statistics in open access represents both a guarantee regarding the quality and seriousness of the information, and an economy of time and resources for scientific research, this editorial is focused on the criteria for willingness of the scientific community to validate the research.

KeYwords: editorial; research validation; open data; Criminal Procedure.

Vivemos na era da informação e os dados estão assumindo um valor científico paulatinamente mais importante, muitas vezes superior em relação aos silogismos, uma vez considerados essenciais. E nessa era da informação, o imenso patrimônio dos dados detidos pelas repartições públicas pode ser colocado à disposição de todos: cidadãos, estudiosos, pesquisadores, instituições, oferecendo uma imagem da sociedade real, provavelmente não estudada nos livros, mas não por isso menos importante ou menos útil aos fins da pesquisa. É suficiente consultar velhos registros para compreender as alterações substanciais que ocorreram na mentalidade e o modo de pesquisar. Registros, aparentemente áridos e sem finalidades, permitem recavar dados precisos para compreender a evolução da sociedade, do direito, da jurisprudência e das tendências doutrinárias.

O conjunto de dados armazenados em todas as esferas institucionais, criados e mantidos com recursos públicos, não devem permanecer relegados nos gabinetes e colocados à disposição somente esporadicamente, sob discricionariedade dos funcionários, mas devem ser acessíveis para toda pessoa que tenha um interesse em utilizá-los. Naturalmente, evitando-se divulgar dados pessoais, ou seja, oferecendo-se dados abertos suficientemente anônimos.

Os entes públicos, partindo das prefeituras até chegar nas Instituições europeias, recolhem dados de todos os tipos. Somente para citar alguns exemplos de uma lista quase infinita, limitada somente pela fantasia: existem dados sobre a proteção dos menores de dezoito anos, informações sobre índices de criminalidade, fluxos de justiça civil e penal, catálogos da superpopulação carcerária, etc. Os dados contidos 
nos arquivos públicos podem ser imperfeitos, incompletos, mas são de qualquer forma dados oficiais, sobre os quais se fundam as escolhas do Estado, que, por sua vez, são embasadas cada vez mais com algoritmos econômicos elaborados segundo regras estatísticas ${ }^{1}$, e sempre menos em consideração das necessidades de tutela dos direitos ${ }^{2}$.

Observa-se que o Estado e a lei são hoje superados por uma gestão política da justiça baseada essencialmente nas necessidades econômicas muito mais do que orientados em favor das necessidades sociais. Estes algoritmos, para poder funcionar eficazmente, necessitam ser continuamente alimentados com dados mais precisos, extensos e atualizados. Os dados públicos, embora frequentemente recolhidos de forma desordenada, redundantes e não coordenados, representam um conjunto de informações fundamentais, constitutivas de uma base para o início de qualquer pesquisa e projeto sérios e consistentes. Certamente os dados públicos não são perfeitos, e em alguns casos exatamente a sua natureza oficial os torna objeto de mistificação; pensamos, por exemplo, nos dados oficiais sobre a imigração, que, por definição não incluem os clandestinos.

Todavia, mesmo com a consciência de alguns limites intrínsecos e dos erros possíveis, com base em dados abertos oficiais, os pesquisadores partem de um elemento standard, publicamente verificável e não facilmente falsificável.

Embora não seja diretamente vinculada aos open data, no ordenamento italiano a Lei 7 de agosto de 1990, n. 241, intitulada Nuove norme in materia di procedimento amministrativo e di diritto di accesso ai documenti amministrativi, constitui uma pedra basilar da renovação administrativa, que marcou a reviravolta de uma administração pública (de agora em diante: AP) autárquica e autoritária à uma AP participativa e transparente. O cidadão não é mais aquele que apresenta um pedido e espera pacientemente que a AP responda, mas tem o direito de participar do procedimento, de acessar os autos, de apresentar observações. Contudo,

1 Cfr. SUPIOT, Alain. La gouvernance par les nombres Broch, 2015, p. 23 s. e FAYOLLE, JACKY. La gouvernance par les nombres est-elle la fin de l'histoire de la statistique?, in <http://www.luxstat.lu/telechargements/JFayolle ConfLux. pdf>. Acesso: dez. 2017.

2 RAHNEMA, Majid; ROBERT, JEAn. La puissance des pauvres, Poche, 2012, p. $47 \mathrm{~s}$. 
esta lei não prevê ainda a publicação periódica de dados específicos e permite o acesso somente se motivado por um legítimo interesse e não dirigido ao controle da AP, mas representou uma mudança fundamental, embora ainda hoje não completamente implementada em todos os escritórios da AP.

Por outro lado, o decreto legislativo de 7 de março de 2005, n. 82 (denominado Codice dell'Amministrazione Digitale, ou, simplesmente, CAD) é permeado pela vontade de favorecer a troca de dados e os format abertos. Em particular, nos sentidos do art. 68.3 CAD por format aberto se entende:

(a) um format de dados tornados públicos, documentados exaustivamente e neutros em relação aos instrumentos tecnológicos necessários para a fruição dos mesmos dados;

(b) dados disponíveis segundo os prazos de uma licença que permita o uso por parte de qualquer pessoa, até mesmo para finalidades comerciais, em forma desagregada;

(c) dados acessíveis através das tecnologias da informação e da comunicação, incluídas as redes telemáticas públicas e privadas, conforme a alínea $a$ ), adaptados ao uso automático por parte de programas elaboradores e com metadados incorporados;

(d) dados disponibilizados gratuitamente através de tecnologias da informação e da comunicação, ou com custos marginais sustentados para a reprodução e divulgação.

O decreto legislativo 14 de março de 2013, n. 33 (intitulado Diritto di accesso civico e gli obblighi di pubblicità, trasparenza e diffusione di informazioni da parte delle pubbliche amministrazioni) representa a primeira intervenção do estado central que obriga os Comuni a estruturar seus sites, pelo menos na secção dedicada à transparência segundo um esquema uniforme em toda a Itália. Esta abordagem não é somente finalizada a favorecer as pesquisas por parte dos estudiosos, como impõe o decreto legislativo citado acima, mas também a tornar os sites em verdadeiros maquinários readable ${ }^{3}$.

3 Embora na maioria das vezes a AP carregue no sistema simples digitalizações, anulando as intenções do legislador. Nesta mesma direção cfr. Diretiva 2013/37/UE do Parlamento Europeu e do Conselho de 26 de junho de 2013, 
Mesmo tratando-se de uma iniciativa privada, sem valor cogente em nível nacional e europeu, o Statuto Internazionale degli Open Data recolhe uma série de indicações e de declarações de princípio sobre os open data. A sua validade é garantida pela própria Agência para a Itália Digital (ou AgID), que, em suas linhas guias de 2016, menciona expressamente dito estatuto aos fins da difusão do conhecimento ${ }^{4}$.

Se todas estas normativas fossem regularmente aplicadas, na Itália e na Europa os dados sobre a administração da justiça seriam utilizáveis livremente. Todavia, falta ainda um esforço para criar uma predisposição de uma forma mentis aberta do pesquisador em relação ao uso dos open data, que conduza a uma utilização dos dados muito maior do que possa fazer um mero vínculo cogente para o patrimônio informativo, do momento que cada AP produz e detêm dados de vital importância para o pesquisador.

Além disso, o fato que alguns dados tornarem-se públicos facilita a revisão e validação dos mesmos: a avaliação de um artigo antes de enviá-lo para ser impresso, seja por parte do comité científico ou pelo peer review, frequentemente é dificultada porque os dados de partida e aqueles elaborados durante a pesquisa não são facilmente verificáveis. Portanto, ou a decisão é tomada na confiança e se avalia exclusivamente o método, ou devem ser empregadas grandes quantidades de recursos para percorrer novamente o caminho da colheita e análise, partindo dos dados de base até chegar às conclusões. Os open data representam, portanto,

segundo a qual os documentos produzidos pelos entes públicos dos estados membros constituem uma ampla bagagem de recursos diversificados e precisos em grau de favorecer a economia do conhecimento e o aprimoramento da pesquisa cientifica. Ver também o Regulamento (UE) 2016/679 do Parlamento Europeu e do Conselho, de 27 de abril de 2016, que entrará em vigor em no dia 25 de maio de 2018. Dito Regulamento, como é notório, supera o atual código da privacy italiano, e, introduzindo a anonimização dos open data e prevenindo seja uma correlação direta com as pessoas, seja indireta através algoritmos e comparações, disciplinam explicitamente o tratamento dos dados para fins de pesquisa e analise estatística. Informações mais detalhadas encontram-se em: <http://www.dati.gov.it/sites/default/files/ LG2016 0.pdf10>. Acesso em: nov. 2017.

4 Na mesma direção cfr. as linhas guias europeias de licença standard e dataset disponíveis em: <http://ec.europa.eu/newsroom/dae/document.cfm?action=display\&doc id=6421>. Acesso em: nov. 2017. 
tanto uma garantia em relação à qualidade e seriedade da informação, como uma economia de tempo e recursos ${ }^{5}$.

Sobre a qualidade e a tipologia, disse-se que muitas vezes os open data são publicados em format pouco legíveis. Por esta razão, Tim Berners-Lee estudou um sistema de pontuação que classifica a fruibilidade dos open data ${ }^{6}$. Estes podem ser:

(1) dados estruturados e codificados em formatos proprietários (como por exemplo um arquivo em $p d f$, uma imagem em jpeg);

(2) dados estruturados, mas codificados em formato proprietário e por esta razão facilmente elaborados por qualquer aplicação informática;

(3) dados estruturados em um formato não proprietário (por exemplo o formato CSV que pode ser aberto por qualquer software);

(4) dados estruturados e codificados em formato não proprietário e dotados de um identificativo único de recurso (URI), como por exemplo o denominado Resource Description Framework $(R D F)$ que aplica ao dado um significado compartilhado (isto é: aquele dado tem o mesmo significado em qualquer língua, em qualquer País);

(5) dados abertos coligados e outros conjuntos de dados abertos (Linked data).

Quanto à classificação por tipologia de open data, nas seções "Ciência" e "Estatística", a Open Knowledge Foundation7 inclui a macrocategoria da justiça penal, com dados e produtos relativos à pesquisa científica, indicadores sociais e jurisdicionais.

Em relação às oportunidades, os open data disponíveis e corretamente administrados constituem um enorme patrimônio, cujos efeitos são positivos para muitas pesquisas, tanto em fornecer uma base aberta e completa na fase embrionária dos projetos, como para favorecer a verificabilidade dos resultados por parte daqueles que devem controlar a validade do método empregado, a congruência das conclusões alcançadas, além

5 Vejam-se, por exemplo <https://www.data.gov/>, criado nos USA em 2009; l'open data inglês www.data.gov.uk; o australiano <data.gov.au>; o canadense $<$ data.gc.ca>; o europeu http://data.europa.eu/euodp/it/home/ e por fim o índice geral mundial <https://www.data.gov/open-gov/ $>$.

6 Ver: <http://5stardata.info/en/>. Acesso: set. 2017.

7 Disponível em: < https://okfn.org/>. Acesso em: set. 2017. 
de correções de erros e anomalias em caso de resultados contraditórios. Trata-se de um círculo virtuoso não facilmente ativável, mas que, uma vez em operação, pode trazer à pesquisa enormes benefícios.

A Itália é provavelmente o país do mundo ocidental onde a obsessão pelos certificados de excelência está modificando mais profundamente os comportamentos dos pesquisadores e das instituições. Com o exercício de avaliação ampla da pesquisa, denominado "avaliação da qualidade da pesquisa" (de agora em diante: $\mathrm{VQR}^{8}$ ), inaugurou-se uma fase de crescente controle centralizado, realizado através de dispositivos aparentemente técnicos. A tentativa de dar uma justificação científica aos métodos de avaliação adotados gerou um inédito conflito entre as dimensões política, científica e ética da pesquisa.

Uma nova correlação parece estabelecer-se entre instrumentos de avaliação e "cientificismo". Por um lado, as técnicas bibliométricas tornam difíceis aquilo que na ciência mais conta: o espírito crítico, as ideias verdadeiramente originais, a abertura de novos espaços, necessariamente não consensuais. Por outro lado, cada vez mais acredita-se que a ciência coincida com a ocupação progressiva e completa da sociedade com os instrumentos que já existem. Desta forma, métodos de otimização, originais e pertinentes de governar a economia ao equilíbrio, individuar a trajetória na pesquisa, guiar o "deep learning” sobre os Big Data.

Promessas mirabolantes são acompanhadas do uso de instrumentos consolidados, compreensíveis aos demais, de fácil sucesso bibliométrico a curto prazo e apresentados com palavras fascinantes: o percurso melhor, o único possível, em economia, na ciência, máquinas para o "deep learning" com ou sem supervisor e com recompensas, que invocam a criança pavloviana que aprende ${ }^{9}$. As muitas promessas garantem financiamentos bilionários, definem os projetos de "excelência"; porém, a dúvida científica, a incerteza, o "resultado negativo", a crítica que explora outros pontos de vista, são excluídos. Assim, projetos riquíssimos conduzem a infinitas publicações e citações, através dos jogos de reenvio recíprocos que garantem novos financiamentos. E o cientificismo acredita

8 Ou seja, o acrônimo italiano de Valutazione della qualità della ricerca.

9 Cfr. também: SKINNER, Burrhus Frederic, The science of learning and the art of teaching. Harvard Educational Review, 1954, p. 86-97. 
no progresso cumulativo da ciência, através de uma única via possível que conduz à verdade, indicada obviamente por quem detém o "pacote de maioria" e onde a bibliometria é a medida e o indicador do progresso.

Todavia, ignora-se um resultado difícil: uma visão profunda e nova requer dezenas de anos para serem compreendidas, assimiladas. Ao invés, o "impact factor" das revistas é calculado com base nos números das citações dos artigos nos dois anos que seguem a publicação $0^{10}$ : com a bibliometria, as redes de computador são usadas para tornar o conhecimento de todos à disposição de todos, novidade fantástica de hoje, mas para normalizar, para pedir a todos que se adequem ao pensamento da maioria, para canalizar todos em direção à escola mais forte ou simplesmente à mais banal, ao sentido comum, à moda.

A avaliação deve ser atribuída a um grupo de pessoas, que mudam e que assumem a responsabilidade de compreender e julgar, de recolher a novidade, entre os limites humanos, não através de máquinas que contam.

Por outro lado, a ciência, entendida como construção ativa do saber científico, é frágil: e esta fragilidade é causada, em primeiro lugar, pelo fato de que o saber científico, e em particular o saber teórico, é cada vez mais contra o saber comum, sempre mais contrário à teoria dominante. É sempre um saber crítico, e isso a torna vulnerável, sobretudo em relação a uma ciência que tenha um forte lado teórico, como o Direito processual penal. De qualquer forma, dita premissa vale até mesmo para a ciência que se debata com uma experimentação. O resultado do matemático, por exemplo, quase sempre parte de uma insatisfação, do dizer "mas não é esse o teorema que teria que ser demonstrado, não é essa a estrutura que conta ou que é necessário inventar para trabalhar com este problema”.

Até mesmo no momento do detalhe, do trabalho quotidiano, ou diante do resultado modesto, existe esta insatisfação em relação ao estado da arte, e que é presente até mesmo em quem é concentrado em uma dimensão abstrata, teórica, que não tem acesso à contrapartida empírica (como no caso do estudioso de Direito processual), onde o querer

10 Para considerações menos sintéticas destas acima expostas, querendo, ver: CAPPARELLI, Bruna; GIACOMOLLI, Nereu J. Editorial: a avaliação do impact Factor na publicação científica de Direito Processual Penal. Revista Brasileira de Direito Processual Penal, v. 3, n. 3, 2017, p. 789-806. 
modificar a própria perspectiva é o motor principal da atividade. Existe sempre a sensação de que algo não está certo, de uma aparente desarmonia no pano de fundo: "não é este o raciocínio a ser seguido, mas um outro".

Pensando aos longos tempos da história, na nossa cultura a raiz deste saber crítico já se manifestava em suas formas essenciais na "ágora" grega, onde pela primeira vez deu-se um espaço ao debate racional. Um debate que é político e democrático, e que desde aquela estreia seguirá tortuosos percursos na história ocidental, através de inúmeras passagens, até o comum renascimento e ao iluminismo. Em qualquer lugar existirá um espaço para a discussão e um espaço para o pensamento, em qualquer lugar pensamento e discussão abrirão o espaço do dissenso. Ali se encontrará pelo menos a sombra da ciência, porque é exatamente isto que conta para o saber científico.

Do dissenso poderá, por exemplo, nascer no Renascimento italiano a pergunta naturalista: pergunta-se como e porque aquelas asas permitem ao pássaro voar, ao invés de olhar a este certo pássaro somente como um símbolo, o sinal da metafísica, segundo uma hermenêutica representativa da salvação ou do pecado, da sorte boa ou má. E estes primeiros modos de se interrogar sobre a natureza se ampliaram e continuam em outros locais de debates: nas cidades, nas universidades, até chegar nas passagens nevrálgicas representadas pelas vivências de Giordano Bruno e Galileo Galilei.

Esta dificuldade, mas também esta força inventiva, ínsita no saber dizer "não" ao pensamento dominante e ao pensamento "de antes" são o coração da criatividade científica, do pensar diferente, que é sempre necessário na ciência como também na democracia. Será novamente necessário esperar o Iluminismo para encontrar um espaço ideal de debate que permitirá novamente reabrir a discussão. No século XIX, importante papel foi desempenhado pela Universidade pública, pela Universidade do Estado: nesta nova instituição será garantido o espaço para o debate, para o dissenso, e isto permitirá uma verdadeira explosão do pensamento científico.

Ademais, o ponto central é que este estreito vínculo entre ciência e democracia possui um entrelaçamento interativo. Se é verdade que o pensamento científico original e criativo sente a necessidade da respiração da democracia, do debate, da possibilidade de dissentir, para poder-se 
difundir, o seu efeito se expande e retorna vivificando-a, até mesmo sobre a democracia. Isto porque, de fato, raciocinar sobre ciência ensina a discutir, ensina a ousar a pensar e desenvolver um raciocínio crítico. Exatamente aquilo que não é aceito e é temido por quem sustenta um pensamento totalitário.

Seja claro que o que conta nesta dúplice relação entre ciência e democracia não é a componente - que é de qualquer forma importante para a democracia - que se baseia na votação da maioria, o momento da consolidação envolta de uma maioria que em seguida constrói ou realiza um projeto de sociedade. Este é um dos elementos constitutivos da democracia, mas não é construção de uma maioria que conta para a ciência. Porque na relação entre ciência e democracia o que mais conta é exatamente aquele espaço-possibilidade do dissenso, do poder não estar todos de acordo, do poder sempre construir uma alternativa. É sempre um pequeno ou um grande não que constrói a novidade científica, a atividade de pesquisa que constrói aquilo que denominamos de progresso científico. Não existe outra forma para que se realize este progresso, se não através deste pequeno ou grande "não", que pode ser local ou global, e que é manifestação intrínseca de cada passagem científica.

O não de frequentemente mudar o ponto de vista, como por exemplo, a abordagem Copérnico e da revolução copernicana: ver o sistema planetário do ponto de vista do sol, ou seja, mudar perspectiva. A perspectiva de Copérnico, observa Van Frassen ${ }^{11}$, provavelmente foi facilitada pela construção prospectiva na pintura italiana, que se difundiu na Europa, porque esta representou a construção de um ponto de vista. Caso afasta-se o ponto de fuga no quadro, modifica-se o ponto de vista na cena. Este será um ulterior elemento, que se une à possibilidade do debate na Europa renascentista, e ajudará Copérnico a ver o sistema solar a partir de outra dimensão, a partir da perspectiva do sol.

Desta forma, a contínua mistura de saber científico com um saber crítico, pode chegar por caminhos externos à técnica científica, como no caso da experiência do infinito na pintura, naquela complexa mistura de metafísica e de realismo, e livre de delimitações disciplinares típicas do Renascimento italiano.

11 FRAASSEN, Bas, C., L'immagine scientifica, Bologna: Clueb, 1985, p. 50 s. 
Postas essas premissas, não se quer sustentar, neste editorial, que na política não seja necessária a maioria e uma construção paritária. Obviamente estes são aspectos imprescindíveis à práxis, além de constituir a finalidade da qualquer atividade política. Porém, acredita-se que na ciência não é este o elemento central. De fato, é no espaço do dissenso - que pode ser construído até mesmo através ou dentro de um espaço de maioria - que se cria a novidade científica. Contudo, é exatamente isto que o neoliberalismo não tolera hoje: em qualquer lugar do mundo, é exatamente esta dinâmica crítica que é colocada em discussão e que produz o atrofiamento do pensamento. E um mecanismo deste disciplinamento da força crítica é representado pela bibliometria, pelos métodos de avaliação automática da produção científica.

A bibliometria é uma técnica específica na qual as máquinas contam o número de citações de um determinado autor. Cada pesquisador, no currículo e em cada avaliação, trará consigo o valor numérico associado a esta nota de maioria da ciência. Este é exatamente o método técnico para impedir a possibilidade de um pequeno grupo ou de indivíduos singulares, que, no dissenso isolado, farão verdadeiramente a ciência. Mas a esta circunstância se adiciona uma sequência de prêmios, em particular para os jovens, o trabalhar em projetos, o fato de que se torne sempre mais difícil obter um local de trabalho certamente fixo.

Algumas universidades americanas estão abolindo a "tenure" (o lugar permanente): fazem-se contratos por cinco anos e, em seguida, se o pesquisador não traz dinheiro suficiente com projetos adequados, principal instrumento de avaliação, deve deixar o lugar para um outro. E isto se adiciona o querer tornar a qualquer custo a pesquisa competitiva, as equipes competitivas e os pesquisadores competitivos: onde, com relação ao que, com quais valores? Quase sempre será a bibliometria, a nota da maioria a premiar o competidor vencedor.

Contudo, aquilo que conta, e é muito difícil na pesquisa científica, é a colaboração. É muito difícil porque os pesquisadores mais capazes são muito seletivos na escolha dos colaboradores e em encontrar um diálogo. Mas quando se colabora o princípio fundamental é que em dois se pensa sempre muito mais que o dobro. Quando se colabora consegue-se fazer, por exemplo, atividades interdisciplinares: não é pensável que um só saiba muitas coisas, mas caso decida-se colaborar é possível criar aquilo 
que mais conta: ou seja, criar um espaço de interdisciplinaridade no qual coexistem mais vozes, embora com dificuldades, mas inventando, graças ao trabalho comum e ao diálogo, estradas novas, entre as disciplinas, que é o quanto de mais fascinante exista no debate científico. Somente a liberdade crítica permite, todavia, a verdadeira audácia teórica, não somente técnica, exatamente da interdisciplinaridade.

Em suma, a construção do conhecimento científico, na história, é sempre relacionada a alguma forma de democracia. É necessária uma "ágora", um local de debate, que permita o dissenso e, portanto, a exploração científica. A ciência é sempre um saber crítico, contrária ao sentido comum, que se constrói com e até mesmo contra o pensamento dominante. Inicia sempre de um “não, não é assim”, até mesmo sobre um fato, uma observação, uma ideia mínima. Certamente é indispensável uma escola de pensamento - não existe um pensador totalmente isolado - mas dentro desta, a novidade típica da ciência nasce através da reflexão de alguns que ousaram ir contra o pensamento dominante.

A ciência é sempre relacionada com aquele componente essencial da democracia que é a presença da minoria que pensa diferente: sem dúvidas a democracia é constituída pelo formar-se de uma maioria que "governa", mas é também constituída pela presença do diferente. Por sua vez, a ciência necessita disto e, portanto, reforça a capacidade de explorar novas vias, de desenvolver um pensamento crítico, e, consequentemente, reforça a democracia.

Ao contrário, se cada vez que se faz uma avaliação cumprir-se-á contando com uma máquina as citações de todos os especialistas de um setor, impede-se o formar-se de um modo de ver diferente, de uma escola de minoria, futura maioria. É possível citar dezenas de empresas científicas fundamentais cujos textos fundadores foram repetidamente rejeitados e, em seguida, citados, retomados, desenvolvidos muitos anos depois. Mas é normal, é certo que seja assim: circulam muitas teses questionáveis e é necessária prudência antes de publicar, citar novidades surpreendentes. Porém caso transforma-se esta prudência ordinária em métrica de avaliação, a ciência finda por falir.

A tendência atual a enquadrar a pesquisa científica de qualquer setor como uma atividade fortemente competitiva para a obtenção de recursos econômicos e para o avanço profissional é justificada com base 
na argumentação segundo a qual, diante de orçamento público limitado, as instituições que representam os cidadãos devem poder efetuar uma escolha o quanto mais informada possível dos entes e dos pesquisadores destinatários do dinheiro público.

Embora esse assunto possa ser compartilhado, este constitui o ponto de partida para a criação de um mecanismo que de fato propicie o objetivo que se pretende alcançar, qual seja, identificar a melhor pesquisa e os melhores pesquisadores e garantir o melhor retorno possível ao investimento público. De fato, não aprofundando o que se entenda por "melhores cientistas" e por "ciência mais promissora", é fácil demonstrar como as políticas atuais, todas apoiadas no uso distorcido e em alguns casos absolutamente infundado de métricas de bibliometria, mais ou menos complexas, especialmente quando tais políticas seguem uma excessiva concentração dos recursos financeiros em poucos institutos e pesquisadores "excelentes", produzem de fato uma profunda distorção das próprias finalidades da pesquisa científica, levando a um exponencial crescimento das publicações manipuladas e falsas. E porque estas, por sua vez, são utilizadas para a avaliação da pesquisa, gera-se um perigoso mecanismo de feedback positivo, com a catastrófica e previsível consequência de que todos os financiamentos são colocados na pior pesquisa.

Em relação às práticas de open peer review, termo que engloba as diferentes modalidades alternativas de revisão aberta entre pares, uma primeira reflexão a ser feita é sobre as melhorias que este método traz ao processo de revisão, tornando-o mais transparente. Mas como recolher uma massa crítica de contribuições que sejam suficientemente relevantes? A open peer review (de agora em diante: OPR) é realmente qualitativamente superior ao sistema de revisão tradicional (single blind ou double blind)?

Quanto ao primeiro problema, propõe-se como forma ótima de OPR não aquela de open crowd review (open participation) que é realizada após a publicação para recolher eventuais comentários ou sugestões, mas aquela baseada no convite a participar ao debate referido a um círculo selecionado de revisores.

Contudo, as diferentes formas de OPR não são, de fato, neutras em relação à comunidade científica, aos grupos de pesquisa, às tipologias (monografia ou artigo) e às modalidades de publicação (plataforma ou revista). 
Quanto ao segundo problema, alguns estudos demonstram a superior qualidade da OPR ${ }^{12}$.

A adoção da OPR na comunidade científica requer uma mudança de paradigma. A tecnologia e a ciência aberta estão favorecendo difusão de diferentes formas de OPR.

Graças à revisão paritária aberta a peer review reconquista o valor de serviço pelas comunidades de pesquisa e exalta o diálogo entre pesquisadores e as diferentes disciplinas. Em relação ao nexo com as normas da ciência a OPR facilita e acelera o reconhecimento público do trabalho do pesquisador. Ela adiciona ao reconhecimento do trabalho de pesquisa até mesmo o reconhecimento do trabalho dos revisores.

No mundo da ciência aberta as normas comunitárias de Merton da ciência recobrem vigor, embora imperfeitas ${ }^{13}$.

A OPR pode ser aplicada a todas as tipologias de resultados da pesquisa, aos artigos científicos, às propostas de projetos, aos dataset. Todavia, a partir de sua definição, ainda devem ser analisados os critérios e as modalidades para assegurar uma avaliação transparente e eficaz para o progresso da pesquisa científica. Isto se enquadra no âmbito da Open Science que recolhe a exigência de analisar as transformações estruturais e tecnológicas no sistema da comunicação científica hodierna.

É exatamente em tal contexto que os princípios de Merton - em particular aqueles de communality e organized skepticism - se tornam importantes pontos de referência ${ }^{14}$.

12 KOWALCZUK, Maria K. et al., Retrospective analysis of the quality of reports by author-suggested and non-author-suggested reviewers in journals operating on open or single-blind peer review models. Disponivel em: <http://bmjopen. bmj.com/content/bmjopen/5/9/e008707.full.pdf>, 2015, p. 3 s. Acesso: set. 2017.

13 Cfr. MERTON, Robert, K. La pratica della ricerca. Frammenti dal taccuino di un sociologo, Roma: Castelvecchi, ult. ed. org. por Sabetta, 2016, p. 15 s.; MERTON, Robert, K. Teoria e struttura sociale. Volume III: Sociologia della conoscenza e sociologia della scienza, Bologna: il Mulino, 2000, p. 67 s. e MERTON, Robert, K. Sulle spalle dei giganti. Poscritto shandiano, Bologna: il Mulino, 1991, p. $53 \mathrm{~s}$.

14 Ver: MERTON, Robert, K. La sociologia della scienza, Milano: Franco Angeli, 1981, p. 33 s. e MERTON, Robert, K. Teoria e struttura sociale. Volume I: teoria sociologica e ricerca empirica, Bologna: il Mulino, 1974, p. 21 s. 


\section{Biblografia}

CAPPARELLI, Bruna; GIACOMOLLI, Nereu J. Editorial: A avaliação do Impact Factor na publicação científica de Direito Processual Penal. Revista Brasileira de Direito Processual Penal, Porto Alegre, v. 3, n. 3, p. 789-806, set.-dez. 2017. https:// doi.org/10.22197/rbdpp.v3i3.108

FAYOLLE, Jacky. La gouvernance par les nombres est-elle la fin de l'histoire de la statistique?, Disponível em: <http://www.luxstat.lu/telechargements/JFayolle ConfLux.pdf>. Acesso: dez. 2017.

FRAASSEN, Bas C., L’immagine scientifica, Bologna: Clueb, 1985.

KOWALCZUK, Maria K. et al., Retrospective analysis of the quality of reports by author-suggested and non-author-suggested reviewers in journals operating on open or single-blind peer review models. Disponível em: <http://bmjopen.bmj.com/ content/bmjopen/5/9/e008707.full.pdf>, 2015, p. 3 s. Acesso: set. 2017.

MERTON, Robert, K. La pratica della ricerca. Frammenti dal taccuino di un sociologo, Roma: Castelvecchi, ult. ed. org. por Sabetta, 2016.

MERTON, Robert, K. Teoria e struttura sociale. Volume III: Sociologia della conoscenza e sociologia della scienza, Bologna: il Mulino, 2000.

MERTON, Robert, K. Sulle spalle dei giganti. Poscritto shandiano, Bologna: il Mulino, 1991.

MERTON, Robert, K. La sociologia della scienza, Milano: Franco Angeli, 1981.

MERTON, Robert, K. Teoria e struttura sociale. Volume I: teoria sociologica e ricerca empirica, Bologna: il Mulino, 1974.

RAHNEMA, Majid; ROBERT, Jean. La puissance des pauvres, Poche, 2012.

SKINNER, Burrhus Frederic, The science of learning and the art of teaching. Harvard Educational Review, 1954, p. 86-97.

SUPIOT, Alain. La gouvernance par les nombres Broch, 2015. 


\section{Informações adicionais e declarações do autor (integridade científica)}

Agradecimentos: Os autores agradecem os professores Vinicius Vasconcellos e Caíque Ribeiro Galícia pela atenta leitura e revisão do texto e pelas valiosas sugestões de melhorias trazidas ao editorial.

Declaração de conflito de interesses (conflict of interest declaration): os autores confirmam que não há conflitos de interesse na realização das pesquisas expostas e na redação deste editorial.

Declaração de autoria (declaration of authorship): todas e somente as pessoas que atendem os requisitos de autoria deste editorial estão listadas como autores; todos os coautores se responsabilizam integralmente por este trabalho em sua totalidade.

- Bruna Capparelli: projeto e esboço inicial, levantamento bibliográfico, revisão bibliográfica, redação, aprovação da versão final.

- Nereu Giacomolli: revisão crítica e complementação bibliográfica, redação, aprovação da versão final.

Declaração de ineditismo e originalidade (declaration of originality): os autores asseguram que o texto aqui publicado não foi divulgado anteriormente em outro meio e que futura republicação somente se realizará com a indicação expressa da referência desta publicação original; também atestam que não há plágio de terceiros ou autoplágio.

\section{COMO CITAR ESTE EDITORIAL:}

CAPPARELLI, Bruna; GIACOMOLLI, Nereu J. Editorial: Instrumentos e práticas para a Ciência aberta no Direito processual penal - perplexidades e algumas possibilidades. Revista Brasileira de Direito Processual Penal, Porto Alegre, vol. 4, n. 1, p. 25-40, jan./abr. 2018. https://doi.org/10.22197/rbdpp.v4i1.137

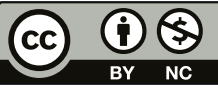

Esta obra está licenciada com uma Licença Creative Commons Atribuição-NãoComercial 4.0 Internacional. 